\title{
Seroprevalence of antibodies to enterovirus 71 and coxsackievirus A16 among people of various age groups in a northeast province of Thailand
}

Hatairat Lerdsamran', Jarunee Prasertsopon ${ }^{1}$, Anek Mungaomklang², Chompunuch Klinmalai ${ }^{3}$, Pirom Noisumdaeng ${ }^{4}$, Kantima Sangsiriwut ${ }^{5}$, Boonrat Tassaneetrithep ${ }^{6}$, Ratigorn Guntapong ${ }^{7}$, Sopon lamsirithaworn ${ }^{8}$ and Pilaipan Puthavathana ${ }^{1,9^{*}}$ (D)

\begin{abstract}
Background: Hand, foot and mouth disease (HFMD) is endemic among population of young children in Thailand. The disease is mostly caused by enterovirus 71 (EV71) and coxsackievirus A16 (CA16).

Methods: This study conducted serosurveillance for neutralizing (NT) antibodies to EV71 subgenotypes B5 and C4a, and to CA16 subgenotypes B1a and B1b, in 579 subjects of various ages using a microneutralization assay in human rhabdomyosarcoma (RD) cells. These test viruses were the major circulating subgenotypes associated with HFMD in Thailand during the study period.
\end{abstract}

Results: We found that the levels of seropositivity against all 4 study viruses were lowest in the age group of 6-11 months, i.e., 5.5\% had antibody to both EV71 subgenotypes, while $14.5 \%$ and $16.4 \%$ had antibody to CA16 subgenotypes B1a and B1b, respectively. The percentages of subjects with antibodies to these 4 viruses gradually increased with age, but were still less than $50 \%$ in children younger than 3 years. These laboratory data were consistent with the epidemiological data collected by the Ministry of Public Health which showed repeatedly that the highest number of HFMD cases was in children aged 1 year. Analyses of amino acid sequences of the test viruses showed $97 \%$ identity between the two subgenotypes of EV71, and $99 \%$ between the two subgenotypes of CA16. Nevertheless, the levels of seropositivity and antibody titer against the two subgenotypes of EV71 and of CA16 were not significantly different.

Conclusions: This study clearly demonstrated NT antibody activity across EV71-B5 and EV71-C4a subgenotypes, and also across CA16-B1a and CA16-B1b subgenotypes. Moreover, there were no significant differences by gender in the seropositive rates and antibody levels to any of the 4 virus subgenotypes.

Keywords: Hand foot and mouth disease, Enterovirus 71, Coxsackievirus A16, Seroprevalence

\footnotetext{
* Correspondence: pilaipan.put@mahidol.ac.th

${ }^{1}$ Center for Research and Innovation, Faculty of Medical Technology, Mahidol

University, Nakhon Pathom 73170, Thailand

${ }^{9}$ Department of Microbiology, Faculty of Medicine Siriraj Hospital, Mahidol

University, Bangkok 10700, Thailand

Full list of author information is available at the end of the article
}

(c) The Author(s). 2018 Open Access This article is distributed under the terms of the Creative Commons Attribution 4.0 International License (http://creativecommons.org/licenses/by/4.0/), which permits unrestricted use, distribution, and reproduction in any medium, provided you give appropriate credit to the original author(s) and the source, provide a link to the Creative Commons license, and indicate if changes were made. The Creative Commons Public Domain Dedication waiver (http://creativecommons.org/publicdomain/zero/1.0/) applies to the data made available in this article, unless otherwise stated. 


\section{Background}

Hand, foot and mouth disease (HFMD) is common in children below the age of 5 . The disease is characterized by acute fever with vesicular rashes or blisters on the palms, soles, and oral mucosa. HFMD can be caused by any of several serotypes of human enteroviruses, most commonly enterovirus 71 (EV71) and coxsackievirus A16 (CA16). The co-circulation of EV71 and CA16 in the same season has been observed in many countries [1-3]. CA16-associated HFMD was first reported in Canada in 1957 [4], and that associated with EV71 was first reported in California in 1969 [5]. At present, HFMD is recognized as an endemic disease in the Asia Pacific region. Outbreaks of EV71-associated HFMD have been reported in many countries in Asia, especially in Japan, the People's Republic of China, Taiwan, Singapore, Vietnam and Cambodia [6-8]. HFMD is usually mild and self-limited, although EV71 might be severe and cause neurological and/or cardiopulmonary complications which may lead to death $[9,10]$. Outbreaks of CA16-associated HFMD have been reported in many countries, but the virus mostly causes mild disease [11-13]. Between 2008 and 2015, CA6 became the predominant causative agent of several HFMD outbreaks in a wide geographical area, including Finland, Singapore, Vietnam, China, Taiwan, Japan and Thailand [14-20]. CA6 was less likely to be associated with severe HFMD than EV71. At present, the incidence of CA6 remains significant.

HFMD was recognized as an emerging disease after an EV71-associated outbreak in Malaysia in 1997 which involved approximately 2628 cases with 29 deaths [21]. In 1998, a larger outbreak of HFMD/herpangina occurred in Taiwan and involved approximately 129,106 cases with 78 deaths [22]. Interestingly, no epidemiological linkage between these two outbreaks was identified. Since 2001, HFMD has been listed in Thailand as a disease requiring notification to the Ministry of Public Health (MOPH) $[23,24]$. At present, HFMD is recognized as endemic in Thailand. The number of cases reported to the MOPH has markedly increased each year, a trend which is probably due to growing awareness of the disease. The incidence of HFMD reaches its peak in rainy season, between June and September; EV71 and CA16 are the two leading causes and co-circulate.

EV71 and CA16 serotypes belong to Family Picornaviridae, Genus Enterovirus, species Enterovirus A. An average genome of picornavirus is about 7500 nucleotides long and encodes for a polyprotein which is cleaved into 4 functional structural proteins: VP1, VP2, VP3 and VP4 of the viral capsid. VP1 is immunodominant and functions as the principal neutralizing (NT) domain. VP2 and VP3 also induce NT antibodies, but VP4 does not [25]. As NT antibodies are protective, subjects with NT antibodies will be immune to subsequent infections by related picornaviruses. Based on the VP1 region, EV71 is classified into 6 genotypes: A, B, C, D, E and F $[26,27]$. Genotype A is the EV71 prototype and comprises only one member, $\mathrm{BrCr}$. Genotype $\mathrm{B}$ is further divided into 5 subgenotypes: B1, B2, B3, B4 and B5; likewise, genotype $\mathrm{C}$ into $\mathrm{C} 1, \mathrm{C} 2, \mathrm{C} 3, \mathrm{C} 4 \mathrm{a}$ and $\mathrm{C} 4 \mathrm{~b}$. Genotypes D, E and $\mathrm{F}$ were identified in India and Africa, and are not subdivided [26, 27]. Similarly, based on VP1, CA16 is divided into 3 subgenotypes: A, B1a and B1b; if based on VP4, CA16 is divided into 3 subgenotypes: A, B and C $[1,28]$. These distinct subgenotypes are distributed in different geographical areas. A subgenotype may circulate for a period of time after emerging and then fade away over time. An example is subgenotype C4b which was introduced into Thailand in 2006 and disappeared in 2008. At present, the situation in Thailand is similar to that in Taiwan and Singapore where B5 and C4a co-circulate, but in Thailand B5 is the predominant subgenotype.

Several epidemiological studies demonstrated NT antibody to only one subgenotype of EV71 and/or CA16 [15, 29-32], while few reported NT antibody across multiple subgenotypes [33, 34]. This prospective seroepidemiological study aimed to determine the frequency of NT antibodies against subgenotypes of EV71 (B5 and C4a) and CA16 (B1a and B1b) in people of various age-groups in Nakhon Ratchasima Province situated in the northeast of Thailand using a cytopathic effect (CPE)-based microneutralization (MN) assay on rhabdomyosarcoma (RD) cell monolayers. In addition, VP1-VP4 amino acid sequences of the test viruses were analyzed to assess antigenic diversity. This information will be useful for understanding the viral antigenic diversity which is important for vaccine development or vaccine selection for a country.

\section{Methods \\ Ethical issues}

This study was approved by two Ethical Committees: the Siriraj Institutional Review Board, Faculty of Medicine Siriraj Hospital, Mahidol University and the Ministry of Public Health Review Board, Nakhon Ratchasima Province. Adult subjects or parents of the child subjects signed the consent form for participation in the study.

\section{Study site}

Nakhon Ratchasima Province is $259 \mathrm{~km}$ from Bangkok. It is the major gateway to the northeast of Thailand. In 2013, this province had a population of 2.6 million, with the second highest population next to Bangkok. Based on data from the Bureau of Epidemiology, MOPH, Thailand, this province had the highest incidence of HFMD cases among the northeast provinces, and ranked third in incidence for all of Thailand. [24]. 


\section{Test sera}

A total of 579 serum samples were collected from subjects who lived in Nakhon Ratchasima Province in 2013. These subjects ranged in age from $<1$ to 60 years old. Samples from children under 5 were the leftover sera from non-HFMD cases after routine investigations for disease diagnosis/treatment in hospitals located in various districts of the province. Sera from those of age older than 5 years were collected from healthy subjects in several communities. The test sera were aliquoted and stored at $-20{ }^{\circ} \mathrm{C}$ until used.

\section{Test viruses}

The test viruses used in MN assays for NT antibodies were: two strains of EV71, SiICRC10/TH/2011 subgenotype B5 (EV71-B5/2011) and SiICRC01/TH/2014 subgenotype C4a (EV71-C4a/2014); two strains of CA16, SiICRC06/TH/2011 subgenotype B1a (CA16-B1a/2011) and SiICRC01/TH/2012 subgenotype B1b (CA16-B1b/ 2012). These viruses were isolated from clinical specimens from HFMD patients in Vero cells (African green monkey kidney cells - ATCC, CCL-81) and propagated in $\mathrm{RD}$ cells (derived from human rhabdomyosarcoma). Both Vero and RD cell lines were grown in Eagle's minimum essential medium (EMEM) (Gibco, NY) supplemented with $10 \%$ fetal bovine serum (FBS) (Gibco); infected RD cell monolayers were maintained in EMEM supplemented with $2 \%$ FBS. The complete VP1 regions of these virus isolates were sequenced and phylogenetically analyzed for genotypic and subgenotypic identification. The virus titers were determined in RD cells and expressed as 50\% tissue culture infectious dose (TCID50) according to the Reed-Muench method [35]. The test viruses were aliquoted and stored at $-80{ }^{\circ} \mathrm{C}$ until used.

\section{Microneutralization assay}

The CPE-based MN assay was conducted in 96-well micro-culture plates. Each test serum was heat inactivated at $56{ }^{\circ} \mathrm{C}$ for $30 \mathrm{~min}$ and serially two-fold diluted with maintenance medium starting from a dilution of 1:10 to $1: 1280$. The assay was performed by mixing $60 \mu \mathrm{l}$ of the diluted serum with $60 \mu \mathrm{l}$ of the test virus suspension at a concentration of 200 TCID50 and incubated at $37{ }^{\circ} \mathrm{C}$ for $2 \mathrm{~h}$. Then, a volume of $100 \mu \mathrm{l}$ of the virus-serum mixture was transferred into a well of RD cell monolayer and further incubated at $37^{\circ} \mathrm{C}$ for $5-6$ days. In order to verify the amount of virus inoculum at the concentration of 100 TCID50, the virus back-titration at doses of $0.1,1,10$, and 100 TCID50 were included in every assay plate, together with positive control with known antibody titer and cell culture controls. Test reactions were run in duplicate. The inoculated cell monolayers were observed for appearance of CPE indicating viral infection. The antibody titer was defined as the reciprocal of the highest serum dilution that protected $50 \%$ of the inoculated cell monolayers from the virus infection, i.e., the last dilution of NT antibody-positive serum which exhibited $\leq 2+$ degrees of CPE. Test sera with NT antibody titers of $\geq 10$ were considered seropositive. To calculate the geometric mean titer (GMT), sera with NT antibody titers of $<10$ were assigned a value of 5 and sera with NT antibody titers of $\geq 1280$ were assigned a value of 1280 .

\section{Viral nucleotide sequencing}

Total RNAs were extracted from the virus suspensions using the QIAamp Viral RNA (QIAGEN, Venlo, Netherlands). The extracted RNAs were used as targets for amplification of VP1 to VP4 regions by reverse transcription-polymerase chain reaction (RT-PCR) using the One Step RT-PCR kit (QIAGEN). Briefly, a total $50 \mu \mathrm{l}$ volume for RT-PCR consisted of $10 \mu$ l of RNA template in master mix containing 1X RT-PCR buffer, $2 \mu$ of enzyme mix, $2 \mu \mathrm{l}$ of dNTP mix, 5 units of RNase inhibitor (Promega Corporation, Madison, WI), and $400 \mathrm{nM}$ of primers. The reaction was carried out in a thermal cycler (GeneAmp PCR system 2400, Applied Biosystems, Foster City, CA). The PCR cycling program consisted of one cycle at $50{ }^{\circ} \mathrm{C}$ for $30 \mathrm{~min}$ and one cycle at $95{ }^{\circ} \mathrm{C}$ for $15 \mathrm{~min}$, followed by 35 cycles at $94{ }^{\circ} \mathrm{C}$ for $30 \mathrm{~s}, 55^{\circ} \mathrm{C}$ for $30 \mathrm{~s}, 72{ }^{\circ} \mathrm{C}$ for $60 \mathrm{~s}$ and a final extension step cycle at $72{ }^{\circ} \mathrm{C}$ for $10 \mathrm{~min}$. The amplified product was electrophoresed in $1.5 \%$ agarose gel in TAE buffer and purified using a QIAEX II gel extraction kit (QIAGEN). The primer sets, shown in an Additional file 1 (Table S1), were designed by our group and used for both RT-PCR and nucleotide sequencing. The purified PCR products were sequenced at Macrogen Korea. The nucleotide sequences were edited and aligned using Bioedit version 7.2.6.1.

\section{Results \\ Prevalence of HFMD, and EV71 and CA16 subgenotypes in Thai children}

According to a report from the Bureau of Epidemiology (BOE), Department of Disease Control, MOPH, from 2007 to 2017, HFMD occurred commonly in children less than 5 years of age (Additional file 2: Figure S1). Throughout the last decade, the highest number of cases was repeatedly observed in children aged one year and gradually declined with older age. The number of HFMD cases reported to the MOPH rose from 10,00020,000 cases in 2007-2011 to 70,000-80,000 in 20162017. Based on complete VP1 sequences, various subgenotypes of EV71 and CA16 were identified during the study period (2013) by both our laboratory and that of the National Institute of Health, Department of Medical Sciences, MOPH (Fig. 1). 


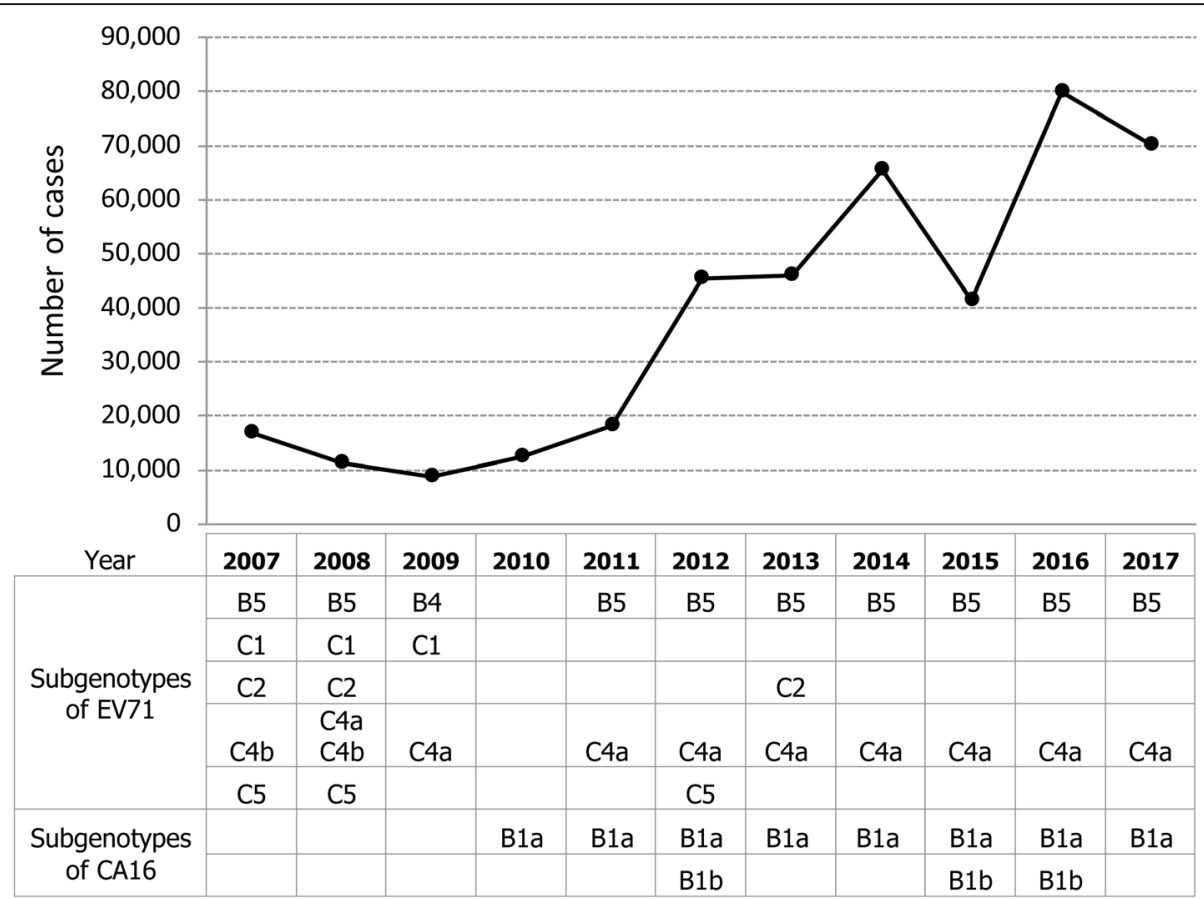

Fig. 1 Number of HFMD cases reported annually by Bureau of Epidemiology, MOPH, Thailand during 2007-2017. Subgenotypes of EV71 and CA16 are identified by our analysis based on sequencing data from our group, the National Institute of Health, Department of Medical Sciences, $\mathrm{MOPH}$, and the GenBank database

\section{Cross-neutralizing antibody against EV71 or CA16 subgenotypes by age and sex}

Sera from a total of 579 subjects from various agegroups were titrated for presence of NT antibodies to EV71-B5, EV71-C4a, CA16-B1a and CA16-B1b at the initial serum dilution of 1:10 using a CPE-based MN assay in RD cells. The presence of NT antibody detected in infants younger than 6 months of age was not accepted as a true result because their sera might contain maternally transferred antibody. Antibody responses to natural infection should account for results in the older age-groups. Distribution of NT antibody titers and GMTs against the 4 subgenotypes in various age-groups among the study subjects are shown in Figs. 2 and 3. The seropositive rates against all 4 study viruses were lowest in the children aged 6-11 months, i.e., 5.5\% had antibody to both subgenotypes of EV71, and $14.5 \%$ and $16.4 \%$ to CA16 subgenotypes B1a and B1b, respectively. The number of subjects with antibodies to these 4 viruses gradually increased with age, but was still less than $50 \%$ in children of age less than 3 years.

The EV71 seropositive rates rose to peaks is the age-group $12-17$ years $(90.2 \%$ for antibody to EV71-B5 and $85.2 \%$ to EV71-C4a), and then declined (Fig. 2a and b). There were neither significant differences in seropositivity (Mann-Whitney U test, $P>0.05$ ) nor antibody levels (paired t-test; $P>0.05$ ) between the B5 and
C4a subgenotypes. The seropositive rates of NT antibody to CA16 were slightly higher than those to EV71. Percentages of subjects with NT antibody to CA16-B1a or CA16-B1b were greater than $90 \%$ in the age-groups of 7-11 years and older (Fig. 3a and b). There were no significant differences in seropositivity (Mann-Whitney U test, $P>0.05$ ) and antibody levels (paired t-test; $P>0.05$ ) between the B1a and B1b subgenotypes. Our study clearly demonstrated the presence of NT antibody activity to the EV71-B5 and EV71-C4a subgenotypes, and also to the CA16-B1a and $\mathrm{CA} 16-\mathrm{B} 1 \mathrm{~b}$ subgenotypes. After merging the data sets, the seroprevalence of EV71 and CA16 NT antibodies in various age-groups, irrespective of subgenotypes, is shown in Fig. 4. Collectively, the study implied that the age-groups younger than 5 years were vulnerable to both EV71 and CA16 infections. A notable feature is that the percent seropositivity to both EV71 and CA16 exceeded those to EV71 or CA16 alone, and that this dual positivity progressively increased from age of 3 years onwards. Greater than $80 \%$ of the subjects in the age-groups older than 7-11 were immune to both serotypes (Table 1).

The total of 579 subjects in this study consisted of 285 males and 294 females (male to female sex ratio of 1:0.97). There were no statistically significant genderbased differences in the number of seropositive subjects (Chi-square test, $P>0.05$ ) nor their GMTs (Mann-Whitney 
A
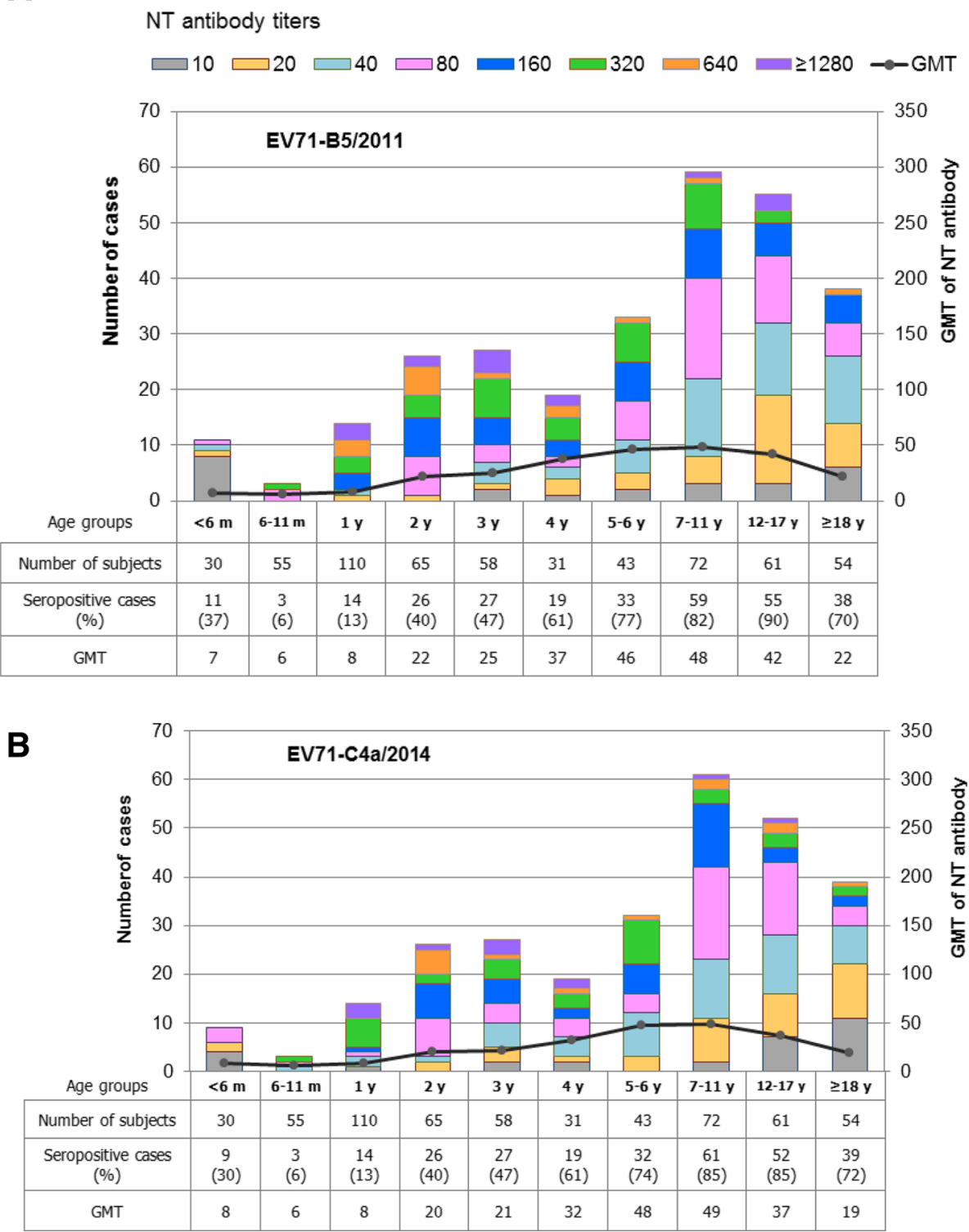

Fig. 2 Distribution of NT antibody titers and GMTs against EV71-B5 (a) and EV71-C4a (b) by age-group

U test, $P>0.05$ ) to any of the 4 test viruses (Additional file 3: Figure $S 2)$.

\section{Amino acid identity between subgenotypes}

Amino acid sequences in the VP1, VP2, VP3 and VP4 regions of EV71-B5 were aligned against those of EV71-C4a, and those of CA16-B1a against CA16-B1b. The results showed an identity of $97 \%$ among 5 strains of the two subgenotypes of EV71, and $99 \%$ among 4 strains of the two subgenotypes of CA16 (Additional file 4: Figure S3 and Additional file 5: Figure S4). However, the amino acid sequences of VP1-VP4 of the two CA16 subgenotypes used in this study were $100 \%$ identical.

\section{Discussion}

HFMD is an uncommon disease in adults, while it is common in very young children. The rarity in adults is probably due to protective immunity induced by previous natural infections. In fact, low seropositive rates are inversely correlated with high prevalences of HFMD in young age-groups. The present study showed that 30 $37 \%$ of children aged $<6$ months were EV71 seropositive, and the seropositive rates decreased to $6 \%$ in the age-group of 6-11 months and 13\% in the age-group of 1 year. Similarly, the prevalence of NT antibody against CA16 was $50-67 \%$ in children aged $<6$ months, and then decreased to $15-16 \%$ in the age-group of $6-11$ months 

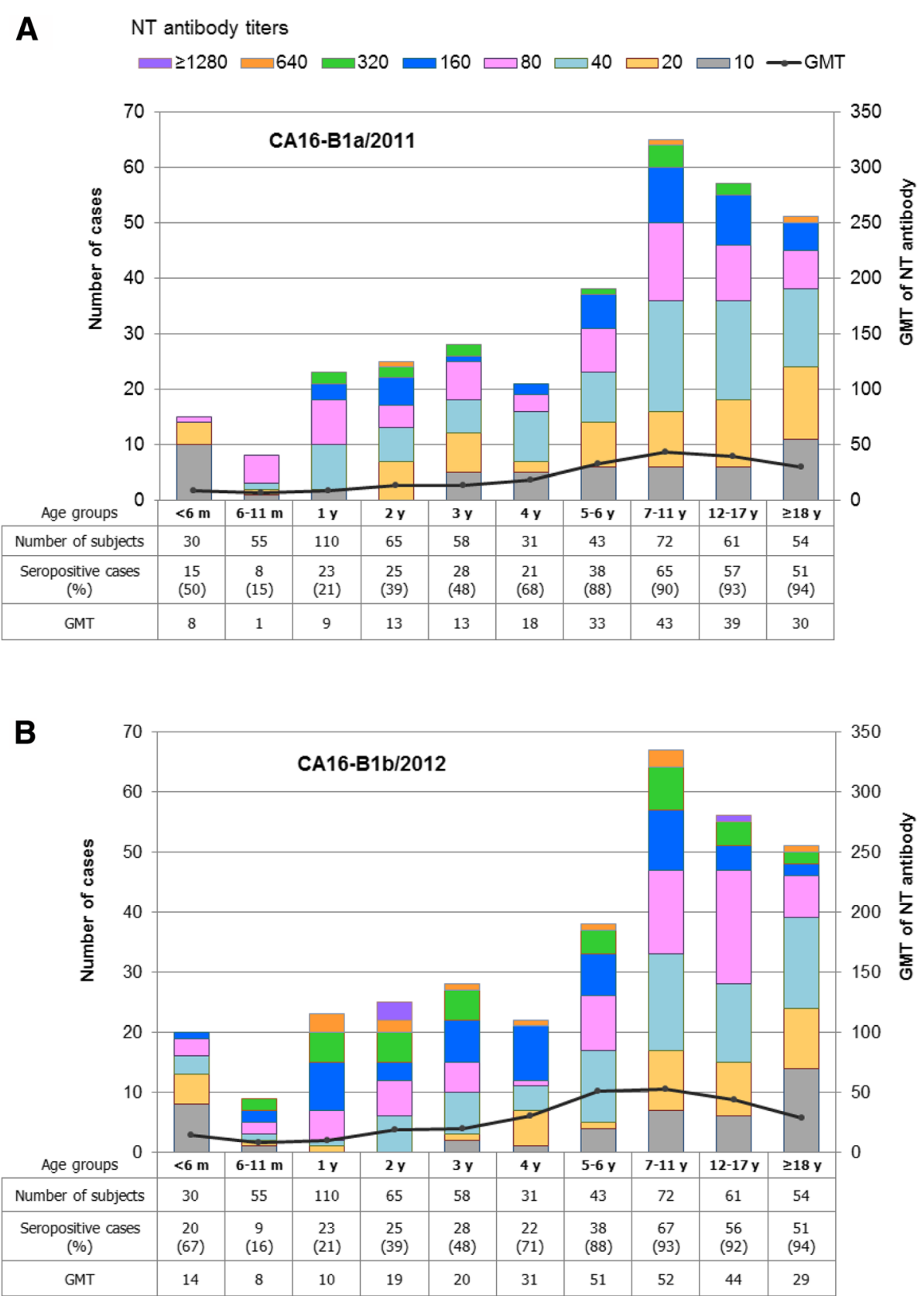

Fig. 3 Distribution of NT antibody titers and GMTs against CA16-B1a (a) and CA16-B1b (b) by age-group

and increased to $21 \%$ in the age-group of 1 year. The higher prevalence of enteroviral antibodies in children younger than 6 months is suggestive of maternally transferred antibody which rapidly declined in the older age-groups. A meta-analysis by other investigators also found that maternal antibody waned almost completely by 5 months of age [32].

The prevalence of enteroviral antibodies varies by country, but the results of this study were similar to those reported previously by investigators from Thailand [36], Singapore [37], Russia [38] and Xiamen City, China [39].
Overall, those data show that the lowest levels of seropositivity $(5-43 \%)$ are found in children aged $1-2$ years, and rises to peak between 7 and 19 years of age. The serological data from Cambodia is obviously different from the others as the seropositivity in children of age $>2$ years in 2006-2011 was higher than $90 \%$ and, despite that, a serious EV71-associated outbreak occurred in 2012 and involved at least 113 severe cases with 54 deaths [31]. Interestingly, EV71 infection was less common in Singapore. A study of serum samples collected during 2008 to 2010 from subjects aged 1-17 years showed that 


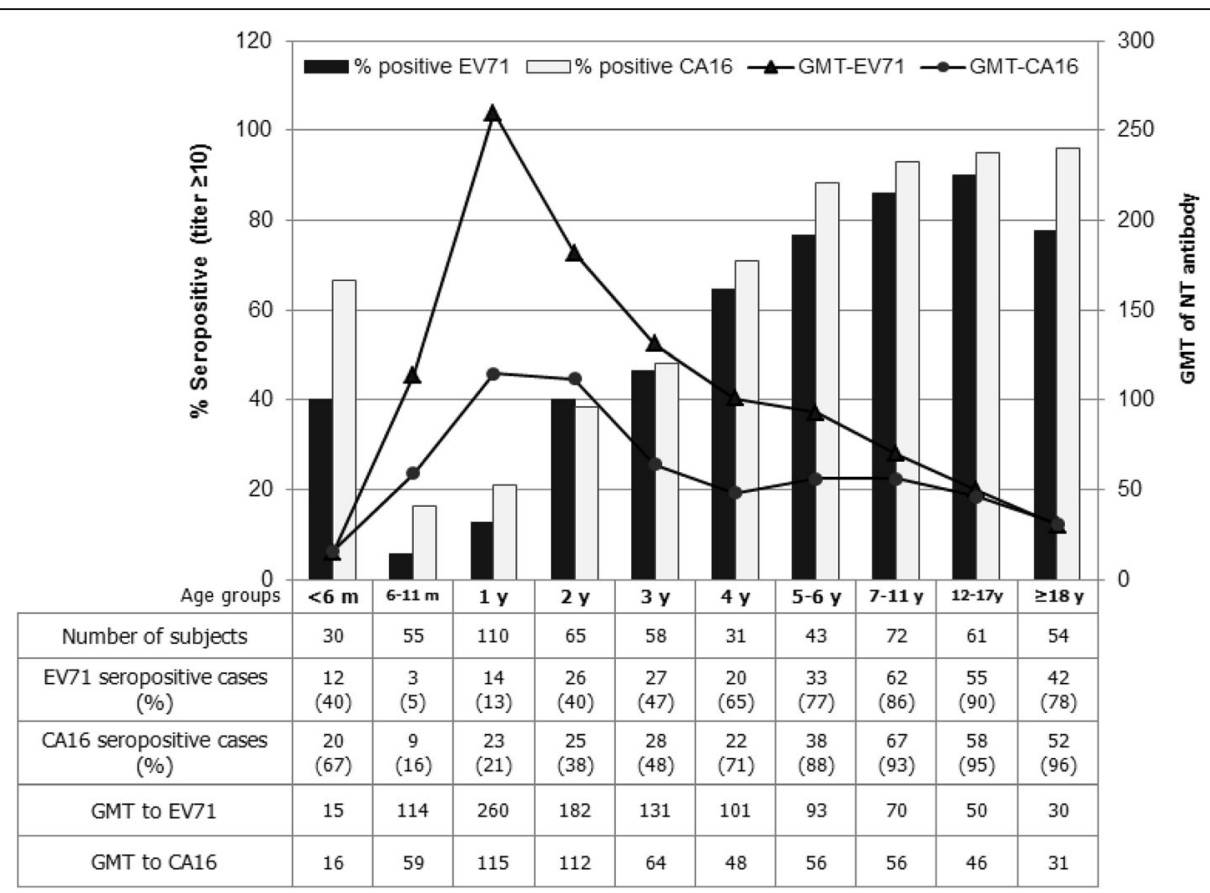

Fig. 4 Seroprevalence of NT antibodies to EV71 and CA16 by age-group, irrespective of the virus subgenotypes. GMTs are based on only the positive serum samples

the seroprevalence of CA6 NT antibody was highest (62.7\%), followed by CA16 (60.6\%) and EV71 (29.3\%) [15]. Approximately $50 \%$ of children in the age-group of $1-$ 6 years had antibody to CA 6 or CA16, while only $15 \%$ had antibody to EV71. This is consistent with a report that antibody induced by inactivated EV71 does not cross protect against CA16 and vice versa [40].

The differences in levels of seropositivity and GMT reported from various studies could not be explained

Table 1 Seropositivity of NT antibody to EV71 and/or CA16 by age groups

\begin{tabular}{|c|c|c|c|c|}
\hline \multirow[t]{2}{*}{ Age } & \multirow[t]{2}{*}{$N$} & \multicolumn{3}{|l|}{$\%$ seropositive } \\
\hline & & $\begin{array}{l}\text { +ve both EV71 } \\
\text { and CA16 }\end{array}$ & $\begin{array}{l}\text { +ve EV71 } \\
\text { only }\end{array}$ & $\begin{array}{l}\text { +ve CA16 } \\
\text { only }\end{array}$ \\
\hline$<6 \mathrm{~m}$ & 30 & 33.3 & 6.7 & 33.3 \\
\hline 6-11 m & 55 & 0.0 & 5.5 & 16.4 \\
\hline $1 y$ & 110 & 0.9 & 11.8 & 20.0 \\
\hline $2 y$ & 65 & 16.9 & 23.1 & 21.5 \\
\hline $3 y$ & 58 & 27.6 & 19.0 & 20.7 \\
\hline $4 y$ & 31 & 41.9 & 22.6 & 29.0 \\
\hline $5-6 y$ & 43 & 67.4 & 9.3 & 20.9 \\
\hline $7-11$ y & 72 & 80.6 & 5.6 & 12.5 \\
\hline $12-17 y$ & 61 & 86.9 & 3.3 & 8.2 \\
\hline$\geq 18 y$ & 54 & 74.1 & 3.7 & 22.2 \\
\hline $\begin{array}{l}\text { Total (All age } \\
\text { groups) }\end{array}$ & 579 & 39.9 & 10.9 & 19.2 \\
\hline
\end{tabular}

by the differences in study populations or geographic location alone. As there is no standard protocol recommended for the MN assay, laboratory techniques and reagents employed in different laboratories are also different. Due to these differences, NT antibody titers may vary and result in some difference in the calculated seroprevalence rates.

Our important findings were that the lowest levels of seropositivity of NT antibodies to EV71 and CA16 were in children of age less than 1 year, and that less than $50 \%$ of children of age younger than 3 years were seropositive. These findings are consistent with the epidemiological data from the $\mathrm{MOPH}$, Thailand, such that most HFMD cases occurred in children aged 1 year or less, followed by those of age less than 2 and 3 years, respectively. Our results suggested that children of age under 3 years were at high risk to get EV71 or CA16 infection. In particular, those in the age-group of $6-$ 11 months were the most vulnerable to contract EV71or CA16-associated HFMD. Among children older than $7-11$ years, $\geq 80 \%$ were immune to both viruses.

There was no difference in seropositivity to EV71 and CA16 by gender found in this study nor that of others $[31,41,42]$. However, a significant difference by gender in the prevalence of antibody to EV71, but not to CA16, is reported from China $[29,30]$.

It is reported that VP1, VP2 and VP3 capsid proteins all contain neutralizing epitopes, but that VP1 contains the major neutralizing domain $[43,44]$. Our analysis on 
intra-subgenotypic variation demonstrated that there were 3 amino acid differences (position 239 in VP2, and positions 663 and 857 in VP1) among 3 strains within the B5 subgenotype; and there were 4 positions of difference between 2 strains of the C4a subgenotype (positions 545 and 557 in VP3, and positions 805 and 814 in VP1). Regarding inter-subgenotypic variation between EV71-B5 and C4a subgenotypes, a total of 24 amino acid differences were found in VP1-VP3, but none in VP4 as shown in (Additional file 4: Figure S3). Nevertheless, the seropositivity and antibody levels, as determined with these two EV71 subgenotypes, were not significantly different. Similar results were also obtained in this study with CA16-B1a and B1b subgenotypes. Our analysis for the intra-subgenotypic variation demonstrated that there were 3 amino acid differences (position 286 in VP2, and positions 729 and 816 in VP1) in 2 strains within the B1a subgenotype; and there were 2 positions of difference between 2 strains of the B1b subgenotype (positions 53 in VP4 and 588 in VP1). Regarding inter-subgenotypic variation among the 4 strains of CA16-B1a and B1b subgenotypes, a total of 5 amino acid differences were found in VP1, VP2, and VP4, but none in VP3 as shown in (Additional file 5: Figure S4). However, the CA16 subgenotypes B1a and B1b used as the test antigens in this study showed the identities of $91.2 \%$ for nucleotide sequence and $100 \%$ for amino acid sequence of the VP1-VP4 regions. Along the entire genomes of these two CA16 subgenotypes, the difference in amino acid sequence of $1.6 \%$ was located in non-structural regions only (data not shown). As such, the significant difference in the level of NT antibodies against these two CA16 subgenotypes in this study was not observed.

EV71 subgenotypic replacement has been shown in different countries during the past 20 years $[27,45]$, including Thailand where subgenotypes B5 and C4a have cocirculated for longer than 5 years. Subgenotypic replacement becomes an important issue in the context of vaccine development. Different EV71 strains were used for vaccine production by different manufacturers. A vaccine strain that induces $\mathrm{NT}$ antibody which can react across subgenotypes is desirable. EV71 vaccine strains used by 3 manufacturers in mainland China belong to subgenotype C4a, while that developed in Taiwan belongs to B4 and that in Singapore to B3 [46]. The results show that NT antibody induced by a $\mathrm{C} 4 \mathrm{a}$ vaccine cross-neutralize EV71 subgenotypes B3, C2, C3, and C5 but not subgenotype A [47]; the NT antibody induced by a $\mathrm{B} 4$ vaccine strongly cross-neutralize $\mathrm{B} 1, \mathrm{~B} 5$ and $\mathrm{C} 4 \mathrm{a}$, but poorly neutralize $\mathrm{C} 4 \mathrm{~b}$ [48]. The information above demonstrates that the relatedness between the vaccine strain and the circulating strain(s) should be considered for vaccine selection in each country. NT antibodies which react across EV71 subgenotypes are also observed in patients with HFMD [34, 49]. It is noted that the cross reactive antibodies in those studies were demonstrated in the vaccinees and HFMD patients. In contrast, our study showed that cross-reactive NT antibody activity against EV71 subgenotypes B5 and C4a existed in the general population.

The collective information from different groups of investigators suggests that protection conferred by EV71 vaccines across subgenotypes may be strain/subgenotype specific. As subgenotypic replacement is common for EV71, evaluation of the efficacy of EV71 vaccines should take account of the circulating strains in each geographical area in each year.

\section{Conclusions}

This study demonstrated that the lowest levels of seropositivity of NT antibodies to EV71 and CA16 were in children of age less than 1 year, and that less than $50 \%$ of children of age younger than 3 years were seropositive. Therefore, children of age younger than 1 year were the most vulnerable to both EV71 and CA16 infections, followed by children of age 2 and 3 years, respectively. These findings are consistent with the epidemiological data from the MOPH, Thailand. We emphasize the importance of serosurveillance to estimate the risk of HFMD outbreaks in child populations. This data also will be useful for vaccine strain selection in the near future.

\section{Additional files}

Additional file 1: Table S1. The primer sets for amplification and nucleotide sequencing VP1-VP4 of EV71 and CA16. (PDF 147 kb)

Additional file 2: Figure S1. Age-related HFMD cases in Thailand during 2007-2017. A summary graph of the data reported by the Bureau of Epidemiology, MOPH, Thailand. (PDF $242 \mathrm{~kb}$ )

Additional file 3: Figure S2. Seropositivity of NT antibodies against EV71 (A) and CA16 (B) by gender. (PDF 393 kb)

Additional file 4: Figure S3. VP1-VP4 amino acid alignment of EV71. (PDF 183 kb)

Additional file 5: Figure S4. VP1-VP4 amino acid alignment of CA16. (PDF $250 \mathrm{~kb}$ )

\section{Abbreviations \\ BOE: Bureau of Epidemiology; CA16: Coxsackievirus A16; CPE: Cytopathic effect; EMEM: Eagle's minimum essential medium; EV71: Enterovirus 71; FBS: Fetal bovine serum; GMT: Geometric mean titer; HFMD: Hand, foot and mouth disease; MN: Microneutralization; $\mathrm{MOPH}$ : the Ministry of Public Health; NT: Neutralizing; RD: Rhabdomyosarcoma; TCID50: 50\% tissue culture infectious dose}

\section{Acknowledgements}

The authors would like to thank all subjects who provided their clinical specimens for this study. We thank the healthcare workers and laboratory teams at Nakhon Ratchasima Province for blood collection and serum processing. We thank Miss Napa Onwimala at the National Institute of Health, Department of Medical Sciences, for technology transfer of the microneutralization test. We also thank Dr. Arthur Brown for English editing. 


\section{Funding}

This study was supported by the National Science and Technology Development Agency (NSTDA). The funders had no role in study design, data collection and analysis, decision to publish, nor preparation of the manuscript.

\section{Availability of data and materials}

All data generated or analysed during this study are included in this published article and its Additional files.

\section{Authors' contributions}

$H L$ performed the experiments, analyzed the results, and drafted the manuscript. JP and CK performed the experiments. AM collected the serum samples. PN and KS performed nucleotide sequencing, analyzed and identified the subgenotype of enteroviruses. BT prepared ethical clearance communications with the Institutional Review Boards. RG contributed part of the data on virus subgenotypes. SI helped in preparing the grant proposal. PP, the grant principal investigator, designed the study and finalized the manuscript. All authors read and approved the manuscript submission.

\section{Ethics approval and consent to participate}

This study was approved by two ethical committees: the Siriraj Institutional Review Board, Faculty of Medicine Siriraj Hospital, Mahidol University, and the Ministry of Public Health Review Board, Nakhon Ratchasima Province. Adult subjects or parents of the child subjects signed the consent form for participation in the study.

\section{Consent for publication}

Not applicable.

\section{Competing interests}

The authors declare that they have no competing interests.

\section{Publisher's Note}

Springer Nature remains neutral with regard to jurisdictional claims in published maps and institutional affiliations.

\section{Author details}

${ }^{1}$ Center for Research and Innovation, Faculty of Medical Technology, Mahidol University, Nakhon Pathom 73170, Thailand. '2Debaratana Nakhon Ratchasima Hospital, Nakhon Ratchasima 30280, Thailand. ${ }^{3}$ Department of Pediatrics, Faculty of Medicine, Ramathibodi Hospital, Mahidol University, Bangkok 10400, Thailand. ${ }^{4}$ Faculty of Public Health, Thammasat University (Rangsit Center), Khlong Luang, Pathum Thani 12121, Thailand. ${ }^{5}$ Department of Preventive and Social Medicine, Faculty of Medicine Siriraj Hospital, Mahidol University, Bangkok 10700, Thailand. ${ }^{6}$ Center of Research Excellence in Immunoregulation, Faculty of Medicine Siriraj Hospital, Mahidol University, Bangkok 10700, Thailand. ${ }^{7}$ National Institute of Health, Department of Medical Sciences, Ministry of Public Health, Nonthaburi 11000, Thailand. ${ }^{8}$ Bureau of General Communicable Diseases, Department of Disease Control, Ministry of Public Health, Nonthaburi 11000, Thailand. ${ }^{9}$ Department of Microbiology, Faculty of Medicine Siriraj Hospital, Mahidol University, Bangkok 10700, Thailand.

\section{Received: 29 May 2018 Accepted: 2 October 2018} Published online: 16 October 2018

\section{References}

1. Li L, He Y, Yang H, Zhu J, Xu X, Dong J, et al. Genetic characteristics of human enterovirus 71 and coxsackievirus A16 circulating from 1999 to 2004 in Shenzhen, People's Republic of China. J Clin Microbiol. 2005;43: 3835-59.

2. Chatproedprai S, Theanboonlers A, Korkong S, Thongmee C, Wananukul S, Poovorawan Y. Clinical and molecular characterization of hand-foot-andmouth disease in Thailand, 2008-2009. Jpn J Infect Dis. 2010;63:229-33.

3. Zhang $X$, Wang $H$, Ding $S$, Wang $X$, Chen $X$, Wo $Y$, et al. Prevalence of enteroviruses in children with and without hand, foot, and mouth disease in China. BMC Infect Dis. 2013;13:606.

4. Robinson CR, Doane FW, Rhodes AJ. Report of an outbreak of febrile illness with pharyngeal lesions and exanthem: Toronto, summer 1957; isolation of group a Coxsackie virus. Can Med Assoc J. 1958;79:615-21.
5. Schmidt NJ, Lennette $\mathrm{EH}, \mathrm{Ho} H \mathrm{H}$. An apparently new enterovirus isolated from patients with disease of the central nervous system. J Infect Dis. 1974; 129:304-9.

6. Sabanathan S, Tan le V, Thwaites L, Wills B, Qui PT, Rogier van Doorn H. Enterovirus 71 related severe hand, foot and mouth disease outbreaks in South-East Asia: current situation and ongoing challenges. J Epidemiol Community Health. 2014;68:500-2.

7. Koh WM, Bogich T, Siegel K, Jin J, Chong EY, Tan CY, et al. The epidemiology of hand, foot and mouth disease in Asia: a systematic review and analysis. Pediatr Infect Dis J. 2016;35:e285-300.

8. Chen M, Ju Y, Chen M, Xie Z, Zhou K, Tan Y, et al. Epidemiological and genetic characteristics of EV71 in hand, foot, and mouth disease in Guangxi, southern China, from 2010 to 2015. PLoS One. 2017:12:e0188640.

9. Huang CC, Liu CC, Chang YC, Chen CY, Wang ST, Yeh TF. Neurologic complications in children with enterovirus 71 infection. N Engl J Med. 1999; 341:936-42

10. Chang LY, Lin TY, Hsu KH, Huang YC, Lin KL, Hsueh C, et al. Clinical features and risk factors of pulmonary oedema after enterovirus-71-related hand, foot, and mouth disease. Lancet. 1999:354:1682-6.

11. Hosoya M, Kawasaki Y, Sato M, Honzumi K, Hayashi A, Hiroshima T, et al. Genetic diversity of coxsackievirus A16 associated with hand, foot, and mouth disease epidemics in Japan from 1983 to 2003. J Clin Microbiol. 2007:45:112-20.

12. Sternak SL, Vrzic VS, Čavlek TV, Aleraj B, Margan IG. Outbreak of hand, foot and mouth disease caused by Coxsackie A16 virus in a childcare centre in Croatia, February to March 2011. Euro Surveill. 2011;16:6-8.

13. Puenpa J, Theamboonlers A, Korkong S, Linsuwanon P, Thongmee C Chatproedprai $S$, et al. Molecular characterization and complete genome analysis of human enterovirus 71 and coxsackievirus A16 from children with hand, foot and mouth disease in Thailand during 2008-2011. Arch Virol. 2011;156:2007-13

14. Osterback R, Vuorinen T, Linna M, Susi P, Hyypiä T, Waris M. Coxsackievirus A6 and hand, foot, and mouth disease, Finland. Emerg Infect Dis. 2009;15: $1485-8$.

15. Ang LW, Tay J, Phoon MC, Hsu JP, Cutter J, James L, et al. Seroepidemiology of coxsackievirus A6, coxsackievirus A16, and enterovirus 71 infections among children and adolescents in Singapore, 2008-2010. PLoS One. 2015; 10:e0127999.

16. Wei SH, Huang YP, Liu MC, Tsou TP, Lin HC, Lin TL, et al. An outbreak of coxsackievirus A6 hand, foot, and mouth disease associated with onychomadesis in Taiwan, 2010. BMC Infect Dis. 2011;11:346.

17. Kanbayashi D, Kaida A, Yamamoto SP, Hirai Y, Kubo H, Fujimori R, et al. Impact of Coxsackievirus A6 emergence on hand, foot, and mouth disease epidemic in Osaka City, Japan. J Med Virol. 2017;89:2116-21.

18. Anh NT, Nhu LNT, Van HMT, Hong NTT, Thanh TT, Hang VTT, et al. Emerging coxsackievirus A6 causing hand, foot and mouth disease, Vietnam. Emerg Infect Dis. 2018:24:654-62.

19. Li JS, Dong GX, Qin M, Feng HR, Yang YJ, Li RX, et al. Outbreak of hand, foot, and mouth disease caused by coxsackievirus A6 in a Juku in Fengtai District, Beijing, China, 2015. Springer Plus. 2016;5:1650.

20. Puenpa J, Chieochansin T, Linsuwanon P, Korkong S, Thongkomplew S, Vichaiwattana $P$, et al. Hand, foot, and mouth disease caused by coxsackievirus A6, Thailand, 2012. Emerg Infect Dis. 2013:19:641-3.

21. Chan LG, Parashar UD, Lye MS, Ong FG, Zaki SR, Alexander JP, et al. Deaths of children during an outbreak of hand, foot, and mouth disease in Sarawak, Malaysia: clinical and pathological characteristics of the disease. Clin Infect Dis. 2000;31:678-83.

22. Ho M, Chen ER, Hsu KH, Twu SJ, Chen KT, Tsai SF, et al. An epidemic of enterovirus 71 infection in Taiwan. N Engl J Med. 1999;341:929-35.

23. Bureau of Emerging Infectious Diseases. Report on the situation of hand, foot and mouth disease (HFMD) in Thailand. 2012. http://beid.ddc.moph.go. th/th 2011/news.php?g=18items=607. Accessed 17 May 2018.

24. Bureau of Epidemiology, Department of Disease Control, MOPH, Thailand. Hand, foot and mouth disease. 2018. http://www.boe.moph.go.th/boedb/ surdata/disease.php?ds=71. Accessed 17 May 2018.

25. Kiener TK, Jia Q, Meng T, Chow VT, Kwang J. A novel universal neutralizing monoclonal antibody against enterovirus 71 that targets the highly conserved "knob" region of VP3 protein. PLoS Negl Trop Dis. 2014:8:e2895.

26. Rao CD, Yergolkar P, Shankarappa KS. Antigenic diversity of enteroviruses associated with nonpolio acute flaccid paralysis, India, 2007-2009. Emerg Infect Dis. 2012;18:1833-40. 
27. Chang PC, Chen SC, Chen KT. The current status of the disease caused by enterovirus 71 infections: epidemiology, pathogenesis, molecular epidemiology, and vaccine development. Int J Environ Res Public Health. 2016;13:890.

28. Zhou F, Kong F, Wang B, McPhie K, Gilbert GL, Dwyer DE. Molecular characterization of enterovirus 71 and coxsackievirus A16 using the $5^{\prime}$ untranslated region and VP1 region. J Med Microbiol. 2011;60:349-58.

29. Li W, Yi L, Su J, Lu J, Ke C, Zeng H, et al. Seroprevalence of human enterovirus 71 and coxsackievirus A16 in Guangdong, China, in pre- and post-2010 HFMD epidemic period. PLoS One. 2013;8:e80515.

30. Wang JX, Zhu SL, Wang J, Lin Y, Pei YW, Sun DP, et al. Seroprevalence of enterovirus A71 and coxsackievirus A16 in healthy people in Shandong province, China. PLoS One. 2016;11:e0162373.

31. Horwood PF, Andronico A, Tarantola A, Salje H, Duong V, Mey C, et al. Seroepidemiology of human enterovirus 71 infection among children, Cambodia. Emerg Infect Dis. 2016;22:92-5

32. Yang B, Wu P, Wu JT, Lau EH, Leung GM, Yu H, et al. Seroprevalence of enterovirus 71 antibody among children in China: a systematic review and meta-analysis. Pediatr Infect Dis J. 2015;34:1399-406.

33. Mizuta K, Aoki Y, Suto A, Ootani K, Katsushima N, Itagaki T, et al. Crossantigenicity among EV71 strains from different genogroups isolated in Yamagata, Japan, between 1990 and 2007. Vaccine. 2009;27:3153-8.

34. Huang ML, Chiang PS, Chia MY, Luo ST, Chang LY, Lin TY, et al. Crossreactive neutralizing antibody responses to enterovirus 71 infections in young children: implications for vaccine development. PLoS Negl Trop Dis. 2013;7:e2067.

35. Reed $\mathrm{L}$, Muench $\mathrm{H}$. A simple method of estimating fifty percent endpoints. Am J Hyg. 1938;27:493-7.

36. Linsuwanon P, Puenpa J, Huang SW, Wang YF, Mauleekoonphairoj J, Wang $J R$, et al. Epidemiology and seroepidemiology of human enterovirus 71 among Thai populations. J Biomed Sci. 2014;21:16.

37. Ooi EE, Phoon MC, Ishak B, Chan SH. Seroepidemiology of human enterovirus 71, Singapore. Emerg Infect Dis. 2002;8:995-7.

38. Akhmadishina LV, Eremeeva TP, Trotsenko OE, Ivanova OE, Mikhailov MI, Lukashev AN. Seroepidemiology and molecular epidemiology of enterovirus 71 in Russia. PLoS One. 2014;9:e97404.

39. Zhu R, Cheng T, Yin Z, Liu D, Xu L, Li Y, et al. Serological survey of neutralizing antibodies to eight major enteroviruses among healthy population. Emerg Microbes Infect. 2018;7:2.

40. Liu CC, Chow YH, Chong P, Klein M. Prospect and challenges for the development of multivalent vaccines against hand, foot and mouth diseases. Vaccine. 2014;32:6177-82.

41. Huang WC, Huang LM, Kao CL, Lu CY, Shao PL, Cheng AL, et al. Seroprevalence of enterovirus 71 and no evidence of crossprotection of enterovirus 71 antibody against the other enteroviruses in kindergarten children in Taipei city. J Microbiol Immunol Infect. 2012;45:96-101.

42. Rabenau HF, Richter M, Doerr HW. Hand, foot and mouth disease: seroprevalence of coxsackie A16 and enterovirus 71 in Germany. Med Microbiol Immunol. 2010;199:45-51.

43. Lee H, Cifuente JO, Ashley RE, Conway JF, Makhov AM, Tano Y, et al. A strain-specific epitope of enterovirus 71 identified by cryo-electron microscopy of the complex with fab from neutralizing antibody. J Virol. 2013:87:11363-70.

44. Arthur Huang KY, Chen MF, Huang YC, Shih SR, Chiu CH, Lin JJ, et al. Epitopeassociated and specificity-focused features of EV71-neutralizing antibody repertoires from plasmablasts of infected children. Nat Commun. 2017;8:762

45. Yi EJ, Shin YJ, Kim JH, Kim TG, Chang SY. Enterovirus 71 infection and vaccines. Clin Exp Vaccine Res. 2017;6:4-14.

46. Chong P, Liu CC, Chow YH, Chou AH, Klein M. Review of enterovirus 71 vaccines. Clin Infect Dis. 2015;60:797-803.

47. In HJ, Lim H, Lee JA, Kim HJ, Kim JW, Hyeon JY, et al. An inactivated handfoot-and-mouth disease vaccine using the enterovirus 71 (C4a) strain isolated from a Korean patient induces a strong immunogenic response in mice. PLoS One. 2017;12:e0178259.

48. Chou AH, Liu CC, Chang JY, Jiang R, Hsieh YC, Tsao A, et al. Formalininactivated EV71 vaccine candidate induced cross-neutralizing antibody against subgenotypes B1, B4, B5 and C4A in adult volunteers. PLoS One. 2013;8:e79783.

49. Zhang $H$, An D, Liu W, Mao Q, Jin J, Xu L, et al. Analysis of cross-reactive neutralizing antibodies in human HFMD serum with an EV71 pseudovirusbased assay. PLoS One. 2014;9:e100545.

\section{Ready to submit your research? Choose BMC and benefit from:}

- fast, convenient online submission

- thorough peer review by experienced researchers in your field

- rapid publication on acceptance

- support for research data, including large and complex data types

- gold Open Access which fosters wider collaboration and increased citations

- maximum visibility for your research: over $100 \mathrm{M}$ website views per year

At BMC, research is always in progress.

Learn more biomedcentral.com/submissions 